\title{
NUMERICAL ANALYSIS OF STRESS IN A POSITIVE DISPLACEMENT EXTERNAL GEAR PUMP LOADED BY THE TENSION OF THE BOLTS
}

\author{
R. Cieślicki ${ }^{*}$, J. Karliński ${ }^{* *}$, P. Osiński ${ }^{* * *}$
}

\begin{abstract}
The article presents the results of the numerical analysis of the state of stress, in a positive displacement external gear pump. The calculations were conducted using the SIMULIA Abaqus software using the finite element method. The model adopted in the work assumes an extremely unfavorable load. The source of the load is the torque at which the bolts connecting the pump elements are tightened. The calculations were verified by conducting an experiment consisting in measuring the deformation of the pump casing using a resistance strain gauge. The results of numerical calculations were compared with the results of the experiment.
\end{abstract}

Keywords: Gear pump, numerical stress analysis, finite element method, resistance strain gauge

\section{Introduction}

Gear pumps with external gearing are among the most widespread types of hydraulic pumps. They are characterized by high efficiency, simple construction, low failure rate and low price in relation to other types of pumps.

The positive displacement pump belongs to the preloaded structure. The bolts connect the casing elements. The proper tightening torque ensures the external tightness of the pump. The article presents static strength calculations for a positive displacement gear pump with external meshing. The finite element method was used for the calculations. Only the load on the bolts is taken into account. Numerical calculations were made using the SIMULA Abaqus software. An extreme, unfavourable load case was adopted. The numerical model was verified by experiment. It consisted of measuring the deformation of the pump casing.

The research was performed as part of the project "Development of high-pressure gear pumps" implemented as part of the Applied Research Program in track A, contract no. PBS3 / A6 / 22/2015, financed by The National Centre for Research and Development.

\section{Gear Pump}

Figure 1 shows the pump view with the key elements selected. The most important elements from the point of view of the scope of work are the pump casing, bolts forming the modeled screw connection, front and cover plates. The pump casing was made of aluminum alloy (PA9/7075). Front and cover plates made of cast iron (EN-GJL-250). The bolts are made of low-alloy steel, heat-treated. The pump is connected with M12 bolts and their strength class is 10.9 (PN-M-82084). Table 1 summarizes key material properties.

\footnotetext{
Rafał Cieślicki MScEng: Faculty of Mechanical Engineering, Wrocław University of Science and Technology; 5 Łukasiewicza st.; 50-371, Wrocław; PL, rafal.cieslicki@pwr.edu.pl

** Jacek Karliński, PhD: Faculty of Mechanical Engineering, Wrocław University of Science and Technology; 5 Łukasiewicza st.; 50-371, Wrocław; PL, jacek.karliński@pwr.edu.pl

*** Piotr Osiński, PhD: Faculty of Mechanical Engineering, Wrocław University of Science and Technology; 5 Łukasiewicza st.; 50-371, Wrocław; PL, piotr.osinski@pwr.edu.pl
} 


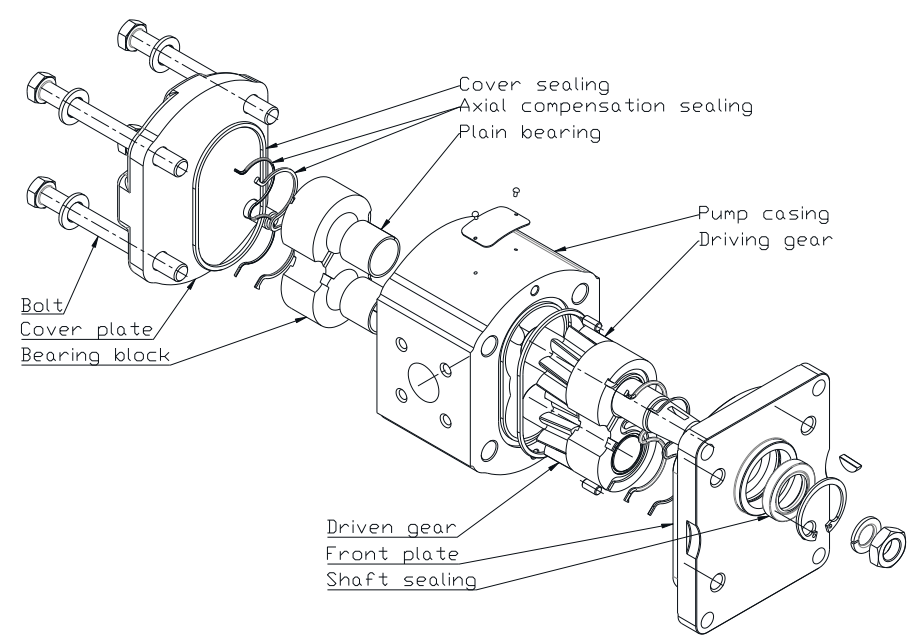

Fig. 1: External gear pump to which the article is referring.

Tab. 1: Material properties

\begin{tabular}{cccc}
\hline Material & PA9 (7075) & 17HNM (1.6587) & EN-GJL-250 \\
\hline Poisson's number [-] & 0.32 & 0.30 & $0 ., 33$ \\
\hline Young's modulus $[\mathrm{MPa}]$ & 7200 & 210000 & 110000 \\
\hline $\mathrm{R}_{\mathrm{p} 0,2}[\mathrm{MPa}]$ & 460 & 830 & - \\
\hline $\mathrm{R}_{\mathrm{m}}[\mathrm{MPa}]$ & 520 & 1180 & 250 \\
\hline
\end{tabular}

\section{Numerical model, boundary conditions and loads}

The pump was attached to the connection plate through bolts. The connection plate has been fixed. Numerical model of the pump (Fig. 2) has been divided by 3D elements of the tetrahedra type (C3D4 and C3D8R). The selection of lower-order finite elements was dictated by a very high demand for operational memory and computing power. The table 2 shows the number of elements and their type for each part of the model.
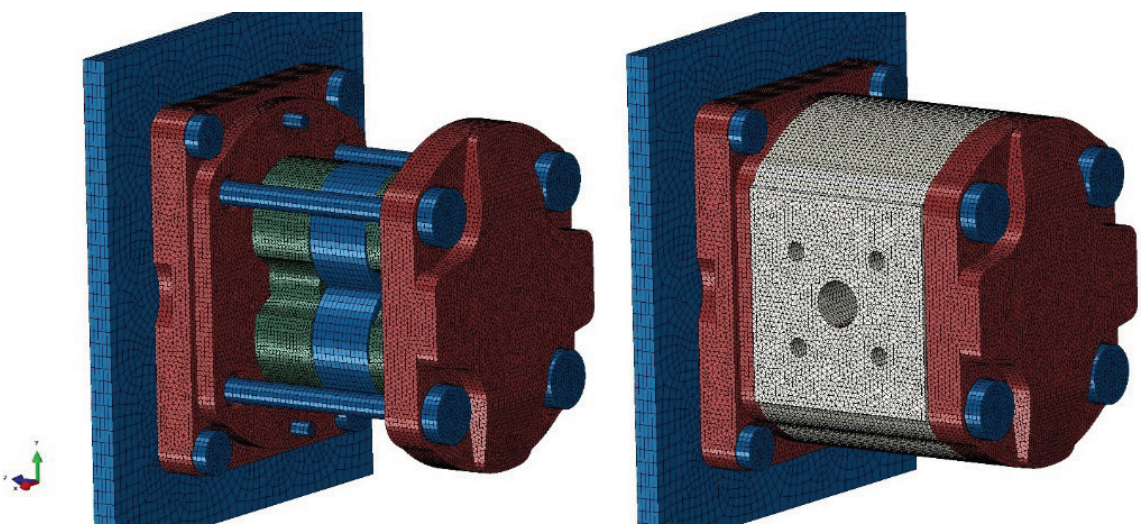

Fig. 2: Numerical model of the gear pump.

Tab. 2: The number and type of finite elements in particular parts of the pump model.

\begin{tabular}{ccccccc}
\hline Part & Casing & $\begin{array}{c}\text { Front } \\
\text { plate }\end{array}$ & $\begin{array}{c}\text { Cover } \\
\text { plate }\end{array}$ & $\begin{array}{c}\text { Bearing } \\
\text { block }\end{array}$ & Gears & Bolt \\
\hline $\begin{array}{c}\text { Number of finite } \\
\text { elements }\end{array}$ & 536447 & 310323 & 228640 & 140901 & 14626 & 2542 \\
\hline $\begin{array}{c}\text { Finit element } \\
\text { type }\end{array}$ & C3D4 & C3D4 & C3D4 & C3D4 & C3D4 & C3D4 \\
\hline
\end{tabular}


The geometry of the model has been simplified by omitting chamfers and roundings. The model includes a simplified outline of gears. The model includes contacts between individual pump parts.

The bolts were loaded with an axial force of $63264 \mathrm{~N}$. The load results from a torque of $89 \mathrm{Nm}$, which is recommended by the pump manufacturer. To calculate the axial force, the coefficient of friction in the bolt connection was assumed to be $\mu=0.07$.

\section{Experiment and model validation}

The experiment consisted in measuring the deformation of the pump casing under the load resulting from tightening the bolts with a torque of $89 \mathrm{Nm}$ using a torque wrench. Measuring apparatus is presented in Fig. 3(a). Location of the measurement points (Fig. 3(b)) was selected based on literature (Kollek, Radziwanowska, 2015, Kollek, Maćkiewicz, 1999, Roliński, 1981)

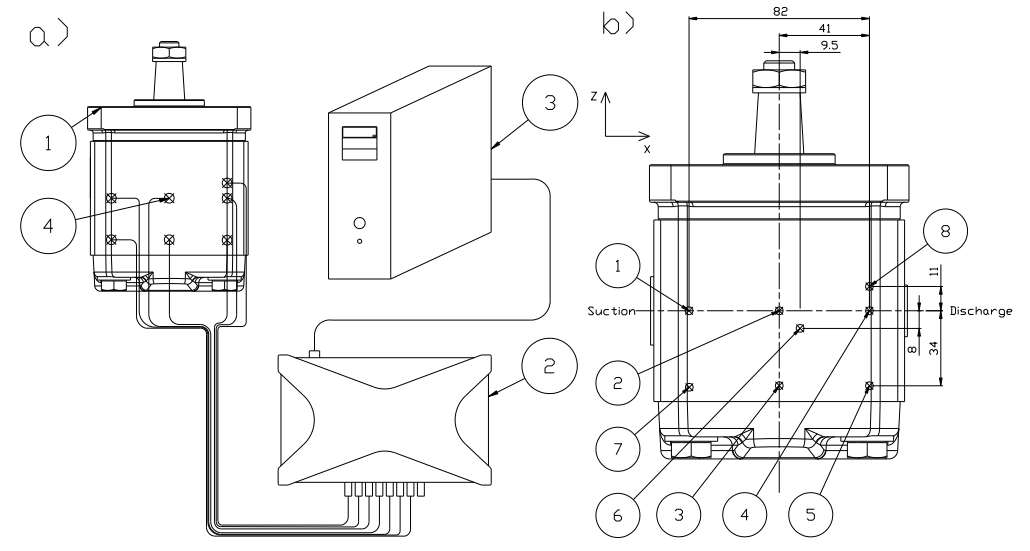

Fig. 3: Diagram of the measuring system (a): 1 - gear pump, 2 - QuantumX MX1615, 3 - PC, 4 - strain gauges. The position of the strain gauges. (b).

To measure the deformation of the pump casing, seven self-compensating strain gauges K-LY43-6/120 (HBM) and one of TFrw-2/120 (TENMEX) type, were used. Each strain gauge was active in a quarterbridge system. The strain gauges were connected in a four-wire configuration. The amplifier was connected to a PC. HMB catman data acquisition software was used to record the measurements.

Table 4 shows the average value of strains recorded during 31 measurements and the results of calculations. From among available strain gauges, measuring points were selected: 1, 4, 6, 7, 8. The remaining points were rejected due to low deformation values not exceeding $20 \mu \mathrm{m} / \mathrm{m}$. The relative differences between numerical calculations and measurements were calculated from the formula (1).

$$
\Delta \varepsilon=\frac{\bar{\varepsilon}-\varepsilon_{\mathrm{FEM}}}{\bar{\varepsilon}} \cdot 100 \%
$$

Tab. 3: The results of measurements and numerical calculations.

\begin{tabular}{cccccc}
\hline Point & $\mathbf{1}$ & $\mathbf{4}$ & $\mathbf{6}$ & $\mathbf{7}$ & $\mathbf{8}$ \\
\hline $\bar{\varepsilon} \pm M U[\mu \mathrm{m} / \mathrm{m}]$ & $139.2 \pm 17.6$ & $115.4 \pm 23.7$ & $-79 \pm 16.2$ & $-516.8 \pm 98.3$ & $-422.2 \pm 34.6$ \\
\hline$\varepsilon_{\mathrm{FEM}}[\mu \mathrm{m} / \mathrm{m}]$ & 180.1 & 145.4 & -60.3 & -693.7 & -484.8 \\
\hline$\Delta \varepsilon$ & 22.7 & 26.0 & 23.7 & 34.2 & 14.8 \\
\hline
\end{tabular}

The relative difference between measurements and calculations is a maximum of $34.2 \%$. Pump casing deformations calculated using the finite element method are greater than the deformations measured during the experiment.

\section{Result of numerical analysis}

As a result of the load, reduced stress distribution was observed according to the Huber-Mises hypothesis (Fig. 4 and 5). Analyzing the results showed the highest reduced stresses in the holes of the front plate and cover plate. They reach $309 \mathrm{MPa}$ and exceed the strength limit of EN-GJL-250 cast iron. Maximum 
stresses occur in elements located on the edge of the holes. Analyzing stresses on the entire hole length, both in the front plate and in the cover plate, they do not exceed $200 \mathrm{MPa}$.

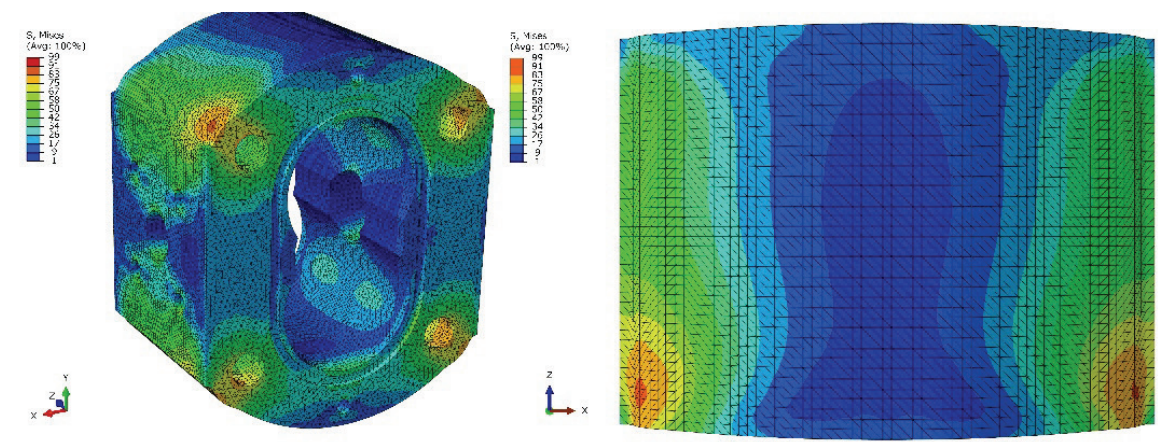

Fig. 4: Reduced stresses according to the Huber-Mises hypothesis in the pump casin.

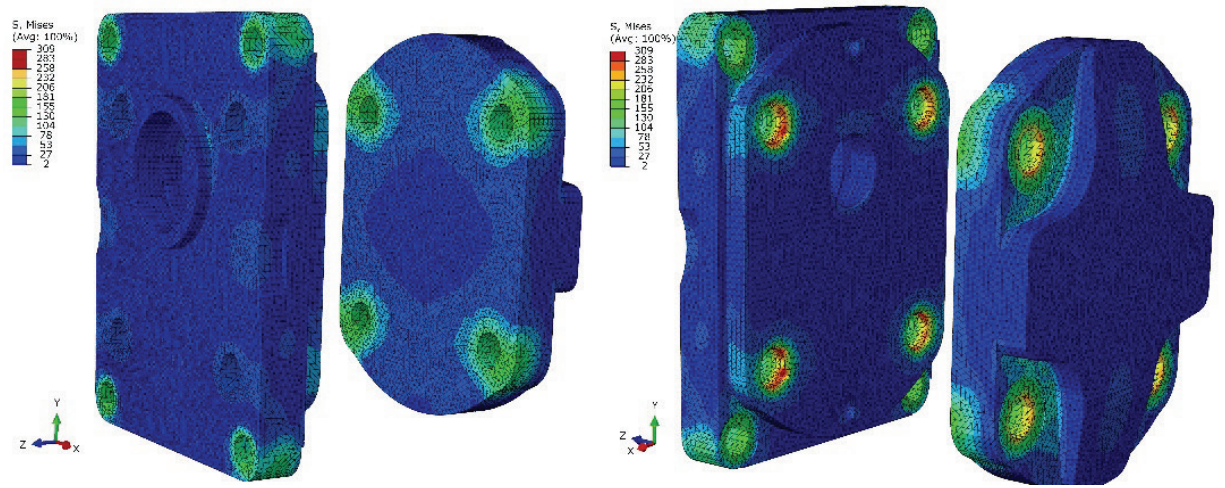

Fig. 5: Reduced stresses according to the Huber-Mises hypothesis in the front plate and cover plate.

The distribution of stresses in the pump casing is symmetrical with respect to the plane parallel to the YZ plane passing through the axes of rotation of the gears. The maximum stresses of $99 \mathrm{MPa}$ occur on the outside of the casing near the screw holes.

\section{Conclusions}

The calculations using the finite element method showed high stresses at the edge of the screw holes connecting the pump elements. They occur in individual finite elements bordering the edge of the hole. It is highly likely that the maximum stress results from the model simplification (sharp edges at the end of the holes). This is indicated by stresses in the further length of the holes. In order to accurately determine the stresses at these points, the size of finite elements should be reduced or higher-order elements should be used.

The experiment carried out confirmed that the applied tension force of bolts is higher than in real conditions. In order to increase the convergence of the numerical model with the measurements, a higher coefficient of friction in the screw connection should be assumed, which will reduce the axial force in bolts

Reduced stresses, acc. the Huber-Mises hypotheses, created in the pump casing, reach almost $100 \mathrm{MPa}$. This value is not significant in the context of the yield strength of aluminum PA9 (7075). However, in the case of calculations of stresses and deformations of gear pumps in conditions of real work, they can have an effect. For this reason, it is recommended that the tension of the bolts connecting the pump casing elements is taken into account in this type of analysis.

\section{References}

Kollek, W., Maćkiewicz, J. (1999). Teoria i obliczanie pomp zębatych. Kadłuby i układy napięte wstępnie. Wrocław: Ossolineum.

Kollek, W., Radziwanowska U.(2015). Energetic efficiency of gear micropumps. Archives of Civil and Mechanical Engineering (15), pp 109-115.

Roliński, Z. (1981). Tensometria oporowa. Podstawy teoretyczne i przykłady zastosowań. Warszawa: Wydawnictwa Naukowo-Techniczne. 